\title{
Parents' burdens of service for children with ASD - implications for service providers
}

\author{
Anu Helkkula \\ CERS, the Centre for Relationship Marketing and Service Management, \\ Hanken School of Economics, Helsinki, Finland \\ Alexander John Buoye \\ Peter J. Tobin College of Business, St John's University, \\ Queens, New York, USA \\ Hyeyoon Choi \\ Department of Human and Consumer Sciences, \\ Ohio University, Athens, Ohio, USA \\ Min Kyung Lee \\ Hankamer School of Business, Baylor University, Waco, Texas, USA \\ Stephanie Q. Liu \\ The Ohio State University, Columbus, Ohio, USA, and \\ Timothy Lee Keiningham \\ Department of Marketing, Peter J. Tobin College of Business, St. John's University, \\ New York, New York, USA and \\ Rockbridge Associates Inc, Great Falls, Virginia, USA
}

\begin{abstract}
Purpose - The purpose of this investigation is to gain insight into parents' perceptions of benefits vs burdens (value) of educational and healthcare service received for their child with ASD. Parents are the main integrators of long-term educational and healthcare service for their child with ASD.

Design/methodology/approach - Design/methodology/approach included (1) a sentiment analysis of discussion forum posts from an autism message board using a rule-based sentiment analysis tool that is specifically attuned to sentiments expressed in social media and (2) a qualitative content analysis of one-on-one interviews with parents of children diagnosed with ASD, complemented with interviews with experienced educators and clinicians. Findings - Findings reveal the link between customized service integration and long-term benefits. Both parents and service providers emphasize the need to integrate healthcare and educational service to create holistic long-term care for a child with ASD. Parents highlight the benefits of varied services, but availability or
\end{abstract}

(C) Anu Helkkula, Alexander John Buoye, Hyeyoon Choi, Min Kyung Lee, Stephanie Q. Liu and Timothy Lee Keiningham. Published by Emerald Publishing Limited. This article is published under the Creative Commons Attribution (CC BY 4.0) licence. Anyone may reproduce, distribute, translate and create derivative works of this article (for both commercial \& non-commercial purposes), subject to full attribution to the original publication and authors. The full terms of this licence may be seen at http://creativecommons.org/licences/by/4.0/legalcode

This project emerged from the Thought Leadership Forum entitled "Service Imperative in Health, Hospitality and Design", hosted by The Cornell Institute of Healthy Futures, Cornell College of Business, May 8-10, 2019 in Ithaca, NY. The authors would thus like to thank the organizers Professor Rohit Verma and Professor Jay Kanpampully. In addition, the authors would like to thank Zeyang Gong and Letao Li, who assisted in the web scraping and sentiment analysis, Fordham University for supporting Dr. Buoye during the early stages of this research, and the Wallenberg Foundations for a grant to Dr. Helkkula to attend the Forum.

Service for children with ASD

Received 14 January 2020 Revised 11 May 2020 11 June 2020

Accepted 11 June 2020
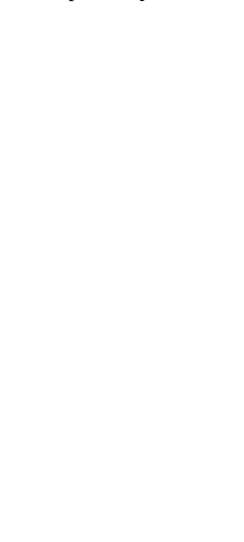
JOSM 31,5

1016 cost are burdens if the service is not publicly provided, or covered by insurance. Service providers' lack of experience with ASD and people's ignorance of the challenges of ASD are burdens.

Practical implications - Ensuring health outcomes for a child with ASD requires an integrated service system and long-term, customer-centric service process because the scope of service covers the child's entire childhood. Customized educational and healthcare service must be allocated and budgeted early in order to reach the goal of a satisfactory service output for each child.

Originality/value - This is the first service research to focus on parents' challenges with obtaining services for their child with ASD. This paper provides service researchers and managers insight into parents' perceptions of educational and healthcare service value (i.e. benefits vs. burdens) received for their child with ASD. These insights into customer-centric perceptions of value may be useful to research and may help service providers to innovate and provide integrated service directly to parents, or indirectly to service providers, who serve children with ASD.

Keywords Value, Service, Educational service, Healthcare service, Benefits, Burdens, ASD, Autism, VBHC, Value-based healthcare

Paper type Research paper

\section{Introduction}

According to the US Department of Health and Human Services Center for Disease Control and Prevention (CDC), one out of every 59 children will be diagnosed with autism spectrum disorder [1] (ASD) (Baio et al., 2018). Variety and severity of symptoms that affect communication, interaction and behavior vary from severe cases requiring $24 / 7$ service to milder inability interacting in social situations. Clearly, a diagnosis of ASD in a child brings emotional costs to the family impacted. However, it also entails significant long-term economic costs to these families, and to the nation as a whole.

In addition, families face enormous challenges in securing proper services for their children with ASD. Research from the Stanford University School of Medicine finds that "the average demand for treatment is 18 times larger than the available supply of caregivers" (Digitale, 2017). One of the major reasons is the lack of adequate compensation to service providers related to the time commitments necessary to treat children with ASD (Hsu, 2018). Moreover, frustration with insurance processes and payments has caused many autism centers to accept only cash payments, which further narrows the options for parents who cannot afford to pay (Hsu, 2018).

The purpose of this investigation is to gain insight into parents' perceptions of benefits vs burdens (value) of educational and healthcare service received for their child with ASD. The findings aim to provide service providers with customer-centric insights to develop service for parents with a child with ASD. In practice, holistic service for a child with ASD requires integrated management of service, and the scope of care extends over the child's whole life. The research question asks: What are parents' perceptions of value (i.e. benefits vs burdens) of educational and healthcare service for their child with ASD? Insight was gained from two sources: (1) an analysis of discussion forum posts from an autism message board and (2) qualitative content analysis of one-on-one interviews with parents of children diagnosed with ASD, complemented with interviews with educators and clinicians.

This exploratory research offers research avenues and managerial insight into burdens that parents have seeking service that helps their child. Access to service (availability and financial difficulties) and integration of services are the biggest burdens for parents. "Value" that parents perceived for the service in this case does not refer to the objective healthcare quality of service (i.e. treatment meeting specifications). Rather, value as perceived by parents relates to the benefits received for the burdens endured; and burdens include both financial and nonfinancial costs (e.g. inconvenience, rudeness, lack of connections, etc.) (Toussaint and Berry, 2013). On the other hand, providers for healthcare and educational service experience firsthand constraints (time, money, need for interaction among service providers, etc.) in delivering the service that they wish to provide children diagnosed with ASD. Service research has called for a value-centric approach to service design and innovation 
(Helkkula et al., 2018). The authors of this paper call for more studies in the customer- and value-centric context of care for parents and children with ASD.

The economic impact to families needing to care for children with ASD is significant. The annual cost in the US exceeds $\$ 11.5 \mathrm{bn}$ (with upper estimates reaching as high as $\$ 60.9 \mathrm{bn}$ ) for healthcare service, special educational service and lost parental productivity (Buescher et al., 2014; Lavelle et al., 2014). Families of a child with ASD can expect an additional $\$ 4,100$ to $\$ 6,200$ per year in healthcare expenses compared to families without ASD (Shimabukuro et al., 2008), and this excludes expenses for behavioral interventions (Amendah et al., 2011). In addition, this study argues that the long-term perspective of healthcare service integrated with educational service requires a holistic, customer- oriented service perspective, where the scope is not short-term outcomes. Finally, this study calls service researchers and managers to contribute to the customer-centric approach to value and design of integrated educational and healthcare service. The findings offer insights to providers of advisory and financial services to help parents manage the long-term costs of service for their child with ASD.

\section{Literature review}

A great deal of research exists on topics relevant to educational and healthcare service for children with ASD. Much of the research in this area focuses on particular settings, treatments and coping mechanisms. However, there is a scarcity of service research related to children with ASD. Below are summaries of the relevant research in these areas broken down by overarching themes addressed in the research.

\section{Burdens and needs in the educational service}

Lack of professionals in educational service. There has been a notable increase at schools in students with autism (Lindsay et al., 2013). Many children with ASD are enrolled in special education systems during their preschool years, or even earlier (Bitterman et al., 2008). Despite the fact that more students with ASD are present in mainstream and special education classrooms, teachers are often expected to create an inclusive learning environment with little or no guidelines on how to provide adequate service (Horrocks et al., 2008; Lindsay et al., 2013). This has been evident with many schools struggling to keep pace in meeting the needs of students with ASD (Humphrey and Lewis, 2008; Symes and Humphrey, 2010). Both teachers and parents stress that more work needs to be done to create inclusive social environments within classrooms (Hinton et al., 2008; McGregor and Campbell, 2001; Smith and Brown, 2000).

With the pervasive characteristics of children with ASD dealing with social development and behavioral problems, it typically results in a need for a wide range of educational needs and services (Bitterman et al., 2008). According to Mandell et al. (2005), children with ASD were more than four times as likely to have educational and school-based services provided to them as compared to children with non-ASD. In addition, Chambers et al. (2003) indicate that children with ASD not only required resources in respect to special education classes but also a variety of other special educational services, such as prolonged day and week times, summer school services and community-based services. However, teachers often face considerable challenges when meeting the needs of these children (Bowe, 2004; Wilmhurst and Brue, 2010; Lindsay et al., 2013). With a lack of resources and inadequate knowledge about ASD, teachers feel unprepared to support children with ASD with academic, social and behavior needs (De Boer and Simpson, 2009; Hinton et al., 2008; Horrocks et al., 2008; Symes and Humphrey, 2010).

This may result in teachers feeling discouraged and children with ASD missing opportunities to reach their full potential (Allen and Cowdery, 2005; Warnock, 2005).

While children with ASD receive more educational services than other children, parents of children with ASD are often somewhat dissatisfied with the educational services being provided (Bitterman et al., 2008). Providing an accepting and inclusive learning climate within
Service for children with ASD 
JOSM 31,5

1018 classrooms is critical, not only in motivating children with ASD to reach their full potential but also for them to feel appreciated, welcome and important (De Winter et al., 1999).

Partnership of educational service providers and parents. Clarke et al. (2009) define parent and teacher relationship as "a child- centered connection between individuals in the home and school settings who share responsibility for supporting the growth and development of children (p. 61)". While services for children with ASD are available in various places, they are more frequently dealt with at home or at school (Matson et al., 2009). The severity of symptoms and behaviors can very among individuals (Chang et al., 2013). Nonetheless, the needs of children with ASD with respect to coordination and communication across school-based services are essential. Some factors that influence parent-teacher relationship include the characteristics of children with ASD, the support ecosystem and customer satisfaction in services being offered (Garbacz, et al., 2016).

Among those, sources of support and satisfaction with services may play a role in influencing parents' willingness to partner with school professionals for child care services (Garbacz et al., 2016).

Early intervention services are regarded as critical in supporting children with ASD (MacDonald et al., 2014). While most children with ASD start receiving services prior to attending kindergarten, services can continue into elementary school and beyond (Garbacz et al., 2016). Although parents of children with ASD often consider themselves to be the primary service coordinators for children with ASD (Carbone et al., 2010), past research has found that parent-teacher relationship can promote and strengthen children's academic as well as behavioral outcomes (Garbacz et al., 2015; Minke et al., 2014).

Families are often overwhelmed in their quest for answers about the nature of their children's disability (Dunlap and Fox, 1999). Realistically, school staff cannot provide individual support to all families that may benefit from this service (Garbacz et al., 2016). To allocate limited resources efficiently, the needs of families of children with ASD must be systematically examined by measuring perceived unmet needs (Magi and Allander, 1981). Family-centered service, which is defined as "practice philosophy in which parents and service providers work in partnership, and supports and services, coincide with changing needs and priorities of the family" (Hodgetts et al., 2013, p. 138) is likely to produce a positive outcome, such as higher parent satisfaction, less parent stress and improved child outcomes (Woodside et al., 2001).

Hodgetts et al. (2013) conducted an in-depth interview with parents to explore how families with a child with ASD experience family-centered service. Their study found that there seems to be a disparity in the perceptions and expectations of family-centered service between parents and professionals, particularly with the sufficiency of information sharing by professionals. For example, professionals might view general information sharing about ASD or finances outside their duties or responsibilities, while parents would like to receive more thorough information from professionals from multiple sectors to enhance their knowledge so that they can provide the best service for their child (Dyke et al., 2006). Also, similar to previous research, the need for information sharing was the most frequently indicated unmet need reported by the parents of a child with ASD (Brown et al, 2012). Without access to information sharing from professionals, parents are not able to fully function as home care therapists for their child, which may increase their frustration, burden and worries.

The majority of past studies revealed that parent educational programs for children with autism have proved effective in promoting parental well-being through learning coping strategies to manage their child's syndromes (Steiner, 2011). Research indicates that parents of children with ASD tend to have unique educational needs as their experiences are quite different from what parents of children with different issues may experience (Plienis et al., 1988). Additional educational outcomes may also include parents' coping and adaptation methods. 
Enhancing coping strategies involves service providers using a strengths-based approach in the assessment of children with ASD (Cosden et al., 2006). Compared to deficit-based models of evaluation and treatment, which puts focus on the child's areas of need, a strengths-based approach views it from the positive aspects of a child's behavior, with emphasis on areas of strength while identifying areas that facilitate development. The use of a strengths-based approach by service providers may result in the potential to influence parental well-being.

Burdens and needs in the healthcare service

Access to service and management of the costs of service. As noted earlier, healthcare service expenditures for a child with ASD are substantial as the child typically needs considerable physical and mental healthcare services and other health-related services. Thus, the high need and utilization of special services for children with ASD place many parents at financial risk. Optimal treatment or special services for children with ASD should not be limited by a burden of healthcare expenses because services limited by cost may negatively affect the breadth and depth of healthcare provided. Lack of service does not produce the most positive outcome that parents or healthcare service providers would hope to observe (Liptak et al., 2006).

Thomas et al. (2016) noted that many parents raising children with ASD are not familiar with health insurance terms. They performed a comparison of healthcare expenditures depending on the type of healthcare insurance for children with ASD and found that there is a significant misalignment between insurance adequacy, expenditures and financial burden (Thomas et al., 2016). Families may have a difficulty in determining the optimal insurance for their needs. The cause of this misalignment is deeply rooted in a lack of understanding of insurance benefits, coverage options and how to determine the best plan that meets their needs. It is necessary to educate the family on the possible options of insurance plans including public insurance options and develop more structured and simplified insurance plan choice strategies (Thomas et al., 2016). In addition, healthcare service providers should give practical guidance to parents regarding the costs of services (Barry et al., 2019).

One of the challenges associated with the treatment of ASD is delay with the ASD diagnostic process (Dunlap and Fox, 1999; Sansosti et al., 2012). Because ASD has no conspicuous physical symptoms and no definitive laboratory test or known biomarker from which to make a diagnosis, arriving at a formal diagnosis for ASD can be challenging prior to a child's second birthday (Wagner and Lockivood, 1994). Other reasons associated with a delay in receiving a diagnosis of ASD are inconsistent and inappropriate screening practices (Sices et al., 2003), inaccurate messages from physicians (Dunlap and Fox, 1999), physicians' slow responses to a family's concerns (Shevell et al., 2001) and physicians' lack of clinical training to treat children with chronic and complex conditions (Chiri and Warfield, 2012). The delay in the ASD diagnostic process can aggravate the severity of developmental delays in children with ASD in terms of language, communication and adaptive functioning, which can increase the overall costs of service going forward, and can also increase parents' level of frustration.

Dental service is the most frequently cited unmet healthcare service need among children with special needs (Lewis et al., 2005). Prior research finds that children with ASD experience significant difficulties and barriers with preventive dental service both at home and in the dental environment (Jaber, 2011; Huebner et al., 2015; Duker et al., 2017) and thus are more easily exposed to poor oral health (and severity of cavities) than neuro-typical children (De Mattei et al., 2007). Barriers to preventive dental service include poor oral self-care, oversensitivity to sensory stimuli, uncooperative children and lack of resources and referral information for effective cavity prevention (Stein et al., 2012; Huebner et al., 2015; Duker et al., 2017). Poor oral health can cause difficulties in eating and speech, as well as oral pain, reduced overall health and quality of life (Owens et al., 2006).

The importance of preventive dental service should be recognized as being on par with a child's other medical service needs. Prior research offers several suggestions for preventive
Service for children with ASD 
JOSM 31,5

1020

dental service for children with ASD. First, cooperation and collaboration between a dentist and parent is critical for preventive dental service. For example, a child's oral care on a daily basis at home, such as toothbrushing under parents' supervision, needs to be performed at least twice a day to prevent early childhood cavities (Huebner et al., 2015). Regular dental exams are also recommended to monitor children's oral health and provide a treatment. Second, the dental environment must be more accommodating to children with ASD than for neuro-typical children. Appropriate techniques for behavior guidance being available to ease a patient's emotional state or limit physical movement during a dental visit are imperative (Duker et al., 2017).

\section{Need for service design and innovation in long-term care for children with ASD}

This investigation focuses on the value perceptions of parents of children with ASD as parents are on the front line in terms of integrating the long-term holistic care of their children.

As ASD requires long-term educational and healthcare services, processes and systems need to be created and aligned with the aims of holistic care of the child. While the study of service design and innovation are central to service marketing and management, to date their attention to healthcare has been limited. Yet, practice reveals many challenges in service process integration for children with ASD. For example, it was only since 1990 that autism was included in the CFR (Code of Federal Regulations) as a special education classification (MacFarlane and Kanaya, 2009). To date, the actual percentage of children with an educational classification of ASD is lower than the number of children being clinically diagnosed with ASD (MacFarlane and Kanaya, 2009). According to the U.S. Census Bureau (2007), the numbers do not account for children attending early elementary schools, parochial or private schools. This implies that approximately one-third of all children who are clinically diagnosed with ASD are not receiving appropriate special educational services under the autism category.

Berry (2019) calls for urgent action in service design and innovation to contribute to a holistic, customer-centric approach in healthcare. Patricio et al. (2018) argue that service design and innovation are crucial for human well-being in healthcare, education and public service.

Relatedly, Helkkula et al. (2018) argue that different approaches of service design and innovation (depicted as archetypes) contribute to value-centric service. Service process focuses on the value-adding phases, while the systemic archetype is central for service providers when they seek to gain valuable outputs within the service ecosystem. To improve customers' perceptions (experiences) of value, service processes and systems need to support the desired output of the service. Specifically, the World Health Organization (WHO) argues that service integration enables people to "receive a continuum of health services, according to their needs, across the different levels of the health system over their lifetimes" (Danaher and Gallan, 2016, p. 433).

\section{Methods, analysis and findings}

The analysis for our research question, section: "What are parents' perceptions of value (i.e. benefits vs. burdens) of educational and healthcare service for their child with ASD?", was performed in two parts: (1) a machine-driven sentiment analysis of discussion forum posts from a prominent online autism message board and (2) qualitative analysis of interviews with parents of children diagnosed with ASD, complemented with interviews with engaged educators and clinicians between June and October 2019.

\section{Sentiment analysis}

Sentiment analysis, also known as opinion mining, is a subfield of natural language processing (NLP). The objective of sentiment analysis is to identify the attitude, evaluations 
and emotions of a speaker/writer based on the computational treatment of subjectivity in a text (Pandey, 2018). To perform the sentiment analysis on the discussion forum data, the NTLK implementation of the VADER (for Valence Aware Dictionary for Sentiment Reasoning) package introduced by Hutto and Gilbert (2014) was used. VADER allows for a more complex analysis compared to other sentiment analysis tools, returning the intensity of sentiments expressed in texts, as well as the polarity. The tool is specifically attuned to sentiments expressed in social media. For more detail on the tool, please refer to Hutto and Gilbert (2014) and Pandey (2018).

Data for the discussion forum post analysis was obtained using the Scrapy module in Python to scrape all forum posts from the "Coping with Life" parents' discussion forum on Wrong Planet. Scrapy is an application framework for crawling web sites and extracting structured data, which can be used for a wide range of applications including data mining, information processing or historical archival [2]. Wrong Planet (i.e. wrongplanet.net) is an online community for individuals with autism spectrum disorders that was started in 2004 by Dan Grover and Alex Plank [3]. From their website: "Wrong Planet is the web community designed for autistic individuals (and parents / professionals of those) with Autism, Asperger's Syndrome, ADHD, PDDs, and other neurological differences. Wrong Planet provides a discussion forum, where members communicate with each other, an article section, with exclusive articles, and how-to guides, a blogging feature, and more" [4]. Wrong Planet has been referenced by the mainstream US media (e.g. Szalavitz, 2007; Deardorff, 2008), as well as in previous academic research (Robertson and Ne'eman, 2008). Web scraping of the forum was completed on September 28, 2019, and at the time contained 196 pages consisting of over 9,000 topics and 150,000+ posts and comments. Posts analyzed dated from November 3, 2004 until September 26, 2019.

A final list of 50 keywords was selected for the sentiment analysis based on a comparison of purposively selected terms against the overall word counts from the scraped data. For each keyword, VADER returns scores for positive, neutral and negative sentiment. These scores were then converted into percentages (so sentiment scores for each term can theoretically range from $-100 \%$ to $+100 \%$ ).

\section{Findings: sentiment analysis}

The sentiment analysis creates an understanding of parents' experiences of raising a child with ASD. Topics in the discussion forum varied widely. The forum is not specifically oriented toward education and health service topics, though those topics arise frequently and organically. Many topics are directly or indirectly connected to healthcare service and educational service, integration of services as well as availability and cost of services: diagnoses, research, options, spend, schedule, violent, skill, program, visual, educational and success. In addition, domestic life topics, such as eating and music, are discussed in the comments and posts. Of the 50 selected keywords that were analyzed, only four demonstrated net negative sentiment scores (burdens): "diagnoses", "violent", "blog" and "eating”. The words with the most positive sentiment (benefits) described aspects that parents considered as benefits: "success", "educational", "visual", "program”, "skill”, "music", "schedule", "options", "research" and "spend" [5]. Some terms like "stimming" or "meltdown", where one might expect a very negative sentiment, are much more mixed, perhaps because they are mentioned within the context of receiving help.

Some parents have burdens to face with respect to the diagnosis of their child. The inability to obtain an ASD diagnosis is a burden for some parents as their eligibility for the help they seek for their child is frequently dependent on that diagnosis.

"Earliest signs of autism spectrum condition, in a child?"; "New diagnosis - normal to doubt it?", "Pediatrician told me my 2 year old son is not Autistic".
Service for children with ASD 
JOSM 31,5

1022

Other postings express burdens that parents face raising a child with ASD. Many of the postings are intimate and focus on that specific discussion forum:

"What not to do during a meltdown - From an autistic adult"; "What would have helped me as an Aspie child", "How do you discipline a child with Asperger's?"; "Do kids on the spectrum potty train later than NT kids?”; “verbal stimming?"; "What age does arm flapping start?”; and "Obsessive empathy for inanimate objects".

Parents also experience that the diagnosis had a considerable impact on their own lives and judged their own behavior.

"Do parents of autistic children get disability SSI?"; “I do not like the mother my son requires me to be"; "Sometimes I HATE my AS step-son".

Adult ASDs also try to help parents by describing what would have helped them in their childhood:

"What not to do during a meltdown - From an autistic adult"; "What would have helped me as an Aspie child".

To summarize the findings of the sentiment analysis, the process of obtaining a diagnosis of ASD is a burden for the parents, as well as behavioral violence that is noticeable in some children's behavior. Routines, schedules, and especially educational service, are perceived as a benefit and valuable. Parents discuss intimate topics in the discussion forum, ranging from ethical questions such as "should Aspies have children" to self-disgust of their own intolerance as a parent for a child with ASD. This inspection of keywords makes clear the centrality of educational and health services to parents' ability to provide care for their children with ASD. Several of these themes emerged in the interviews will be shown in the following section.

\section{Findings: interviews}

The interview respondents were chosen based on the access and sample relevance, which refers to the degree the respondents represent the object of the study (Landers and Behrend, 2015). All parents were caretakers of their child with ASD. The complementary respondents of healthcare service providers and educational service providers had experience working with children with ASD.

The parents of children with ASD in the study come from a variety of backgrounds and diagnoses. Some were diagnosed as early as 18 months, others at 3.5 years or later. Some children with ASD are high functioning, while others are low. Interviews followed a common format and encouraged respondents to personal storytelling. In the USA., interview questions were mailed/emailed to prospective respondents. In Finland, interviews were conducted face to face (duration 30-56 min). In total, responses were obtained from 40 respondents: 26 parents, nine educational service providers and five healthcare service providers. The respondents' nationalities included American (35), Finnish (4) and Korean (1). Respondents ranged from ages 24 to 63 with an average age of 39.6. In terms of gender, 30 respondents were female and 10 were male. Ages of the children with autism of parents interviewed ranged from ages four to 22 (including three adult children, ages 18, 19 and 22) (see Table 1).

Transcripts were analyzed qualitatively and manually coded. Themes of the analysis were based on the research question addressing parents' perceptions of value (i.e. benefits vs burdens) of educational and healthcare service for the child with ASD. Parents, educators and clinician interviews were analyzed separately. All researchers read the transcripts several times, and benefits and burdens were coded, discussed and mutually agreed upon. Major service benefits and burdens for parents aligned below the major themes in findings, even if the symptoms that affect communication, interaction and behavior vary from severe to milder inability interacting in social situations. 


\begin{tabular}{|c|c|c|c|c|c|}
\hline & $\begin{array}{l}\text { Gender, age, } \\
\text { nationality }\end{array}$ & Profession & $\begin{array}{l}\text { Interview online/ } \\
\text { face-to-face }\end{array}$ & $\begin{array}{l}\text { Child's } \\
\text { age }\end{array}$ & $\begin{array}{l}\text { Service for } \\
\text { children with }\end{array}$ \\
\hline \multicolumn{6}{|c|}{ Parents } \\
\hline 1 & F, 57, USA & full time, credit union officer & Done online & 22 & \\
\hline 2 & $\mathrm{~F}, 46, \mathrm{USA}$ & Professor & Face-to-face & 8 & \\
\hline 3 & F, 49, USA & Preschool teacher & Done online & 9 & \\
\hline 4 & M, 32, USA & Construction & Done online & 13 & 1023 \\
\hline 5 & $\mathrm{~F}, 40, \mathrm{USA}$ & Accountant & Done online & 9 & \\
\hline 6 & $\mathrm{~F}, 35, \mathrm{USA}$ & Sales director & Done online & 12 & \\
\hline 7 & $\mathrm{~F}, 30$, USA & Registered nurse & Done online & 4 & \\
\hline 8 & $\mathrm{~F}, 38, \mathrm{USA}$ & Admin & Done online & 8 & \\
\hline 9 & $\mathrm{~F}, 46$, USA & Administration & Done online & 12 & \\
\hline 10 & M, 38, USA & Social services & Done online & 14 & \\
\hline 11 & M, 35, USA & Sales & Done online & 14 & \\
\hline 12 & $\mathrm{~F}, 24, \mathrm{USA}$ & Stay At home & Done online & 4 & \\
\hline 13 & M, 35, USA & Dentist & Done online & 5 & \\
\hline 14 & M, 29, USA & Sales manager & Done online & 5 & \\
\hline 15 & $\mathrm{~F}, 37, \mathrm{USA}$ & Homemaker, caregiver & Done online & 8 & \\
\hline 16 & M, 43, USA & IT manager & Done online & 7 & \\
\hline 17 & $\mathrm{~F}, 34, \mathrm{USA}$ & Marketing line manager & Done online & 4 & \\
\hline 18 & M, 35, USA & Software engineer & Done online & 10 & \\
\hline 19 & $\mathrm{~F}, 37, \mathrm{USA}$ & Retail & Done online & 5 & \\
\hline 20 & $\mathrm{~F}, 44, \mathrm{USA}$ & Medical office admin & Done online & 17 & \\
\hline 21 & $\mathrm{~F}, 33, \mathrm{KOR}$ & Graduate student, designer & Done online & 3 & \\
\hline 22 & $\mathrm{~F}, 47, \mathrm{USA}$ & Education - administrative assistant & Done online & 9 & \\
\hline 23 & $\mathrm{~F}, 37, \mathrm{USA}$ & PhD student & Done online & 7 & \\
\hline 24 & $\mathrm{~F}, 53, \mathrm{USA}$ & Librarian & Done online & 10 & \\
\hline 25 & $\mathrm{~F}, 52$, USA & Laboratory coordinator & Done online & 19 & \\
\hline 26 & M, 53, FIN & Professor & Face-to-face & 18 & \\
\hline & 126 & & Range $4-22$ & & \\
\hline \multicolumn{6}{|c|}{ Educational service providers } \\
\hline 1 & M, 40, USA & $\begin{array}{l}\text { Board-certified behavior analyst (school } \\
\text { district) }\end{array}$ & Done online & & \\
\hline 2 & $\mathrm{~F}, 34, \mathrm{USA}$ & Special education teacher & Face-to-face & & \\
\hline 3 & $\mathrm{~F}, 45, \mathrm{USA}$ & Teacher assistant & Done online & & \\
\hline 4 & $\mathrm{~F}, 49$, USA & Associate & Done online & & \\
\hline 5 & $\mathrm{~F}, 25$, USA & Special education teacher & Done online & & \\
\hline 6 & $\mathrm{~F}, 54, \mathrm{FIN}$ & Kindergarten director & Face-to-face & & \\
\hline 7 & $\mathrm{~F}, 44, \mathrm{USA}$ & Board-certified behavior analyst & Done online & & \\
\hline 8 & $\mathrm{~F}, 36, \mathrm{KOR}$ & Assistant professor of special education & Done online & & \\
\hline 9 & $\mathrm{~F}, 33$, USA & $\begin{array}{l}\text { Counselor/therapist, licensed professional } \\
\text { counselor (LPC) }\end{array}$ & Done online & & \\
\hline \multirow{2}{*}{\multicolumn{6}{|c|}{$\begin{array}{l}\text { Total } 9 \\
\text { Health care service providers }\end{array}$}} \\
\hline & & & & & \\
\hline 1 & $\mathrm{~F}, 35, \mathrm{USA}$ & Dentist & Done online & & \\
\hline 2 & M, 33, USA & Dentist & Done online & & \\
\hline 3 & $\mathrm{~F}, 27, \mathrm{USA}$ & Speech-language pathologist & Done online & & \\
\hline 4 & $\mathrm{~F}, 63, \mathrm{FIN}$ & MD, school and maternity and child GP care & Face-to-face & & \\
\hline 5 & $\mathrm{M}, 28, \mathrm{FIN}$ & MD, hospital, department of children's and & Face-to-face & & \\
\hline \multirow{2}{*}{\multicolumn{5}{|c|}{$\begin{array}{l}\text { Total } 5 \\
\text { Total number of all respondents } 40\end{array}$}} & Respondents \\
\hline & & & & & \\
\hline
\end{tabular}


JOSM 31,5

1024
Findings: parent interviews

Integration of educational and healthcare service. Parents have challenges receiving help for their child with ASD. Integration of the educational and healthcare service is a burden. Parents want holistic care for their child with ASD, and the silos between different types of care are challenging.

The care system is bureaucratic. Holistic view is the best for children with autism. (Parent 129:5)

Many parents struggle managing and integrating the care for their child with ASD. Parents perceive burdens specifically navigating healthcare insurance and educational systems with regard to the necessary customization of service, as autism manifests itself very differently from patient to patient. Service between different school districts and support for parents varies a lot. Thus, integrated educational and health care for children with ASD is a systemic problem at the policy level.

We are very happy with the current school he is at and the level of attention, services he is receiving. They (1) care about each child with special needs and (2) provide the resources necessary to help the child develop. But this is an exception to what exists out there compared to most educational districts. There are issues of (1) lack of information on special education resources that each school district offers, (2) competence and education of people involved in the districts in special education, (3) a general lack of care and concern for children with special needs, (4) a conflict of interest in which case managers make decisions under cost pressure from school districts rather than what is in the best interest of the child, (5) a general lack of appropriate services in school districts, and (6) putting parents with limited income and education at a huge disadvantage due to language and knowledge limitations, lack of access to information about their rights (parents -as mandated by law - are just handed a guidebook for "special education rights" by case managers that is difficult to read, understand and interpret) and not having the resources they need to have legal representation when needed to be their child's advocate. Major improvements would need to address all these issues and require systemic changes." (Parent 139:6)

Major benefits for parents of educational service. Several respondents express a great deal of satisfaction with their child's educational service. In addition to specific support staff, ASD knowledgeable teachers are also highlighted - that is, teachers who have a good understanding of their children's needs (e.g. patience with stimming behaviors) are seen as a great benefit. These knowledgeable teachers can help prevent meltdowns by taking simple steps like not forcing children to participate in group work.

Respondents also mention small class sizes and discounts on tuition/rates as benefits.

They are really focusing on social behaviors and empathy. They are helping him work through doing things that he would rather not do - he's learning skills on how to put off immediate gratification and knowing that some things need to be done even if he does not want to do them. (Parent 60:3)

We as a family learned sign language, his school was amazing in helping both us and him learn to communicate. His teachers are also a Godsend to helping teach us how to deal with the behavior aspects. (Parent 71:3)

Major burdens for parents of educational service. A prevalent theme for potential improvements is more teacher training. General frustration and the need for patience are frequently mentioned, whether that refers to dealing with meltdowns, avoiding certain social situations or difficulty mastering social skills or even just eating.

I would say hire staff that is really knowledgeable and not ones that looked like they just Google information. (Parent 144:6)

General education teachers do not in any way understand autism. I would like to think that is better now. We would get calls from teachers or administrators telling us that my son was blurting out in class or waving his hands in his face or stacking books up in class and could we get him to stop! 
Typical behavior from an autistic child. They expected him to behave just as a non-autistic child. School got better once my son passed through puberty. He actually had some class electives that he enjoyed in high school. (Parent 62:3)

Parents perceive that increased interaction/integration between different grades is needed as the change of routines and environment is challenging for children with ASD.

I think the mapping process to the next grade should be more thought out. Does the education requirements, for the next grade, require a different plan or different level of support? Is the routine going to change than what the student is accustomed to? For example, grades 1-3, the students stay in one classroom. Grades 4-6 the student rotates between classrooms. The change from 3 rd to 4 th is different and should require a thought out plan to support the routine change. (Parent 132:6)

In the educational service, there are many other groups of people involved in addition to pedagogical professionals (e.g. other parents, pupils, supportive staff). A common theme raised is dealing with the ignorance of others, especially with respect to the children's difficulty with understanding social norms. Several parents mention acceptance of their child - avoiding their own temptation to try to "fix" or "cure" them, as well as the ignorance of others who do not understand why the children cannot simply be "cured".

Isolation, prejudice, ignorance, misinformation, people believing there is or should be a cure for autism. This sensitive neurotype needs nurturing, calm, and temperate surroundings and the world is not made this way. Challenges are unending, school refusal, pathological demand avoidance, ocd [obsessive compulsive disorder] tendencies, anything to do with relating to peers. (Parent 85:4)

Parents want more options in terms of content. On one hand, parents want to match the educational content to their child' s competences; on the other hand, they want to the children to expand their comfort zone rather than to focus only on things they are comfortable with.

Children with ASD are expected to complete an academic curriculum that more than likely will not benefit them as much as a curriculum of life skills. My son had to complete Chemistry, Biology and Geometry. I understand that he needed reading and English classes but the others he did not even begin to understand. He was in special education classes but the curriculum is the same for all students in this state. (Parent 62:3)

My son loves things that he is good at. It takes a lot of effort to push him outside his comfort zone. (Parent 156:6)

A few respondents express anxiety about the future of their child with ASD. Many express a desire for their child to one day live a "normal life". Where that was not a realistic expectation, others spoke of "progression". Several others hope for their children to achieve independence and happiness. Some use the word "thrive". In many cases, these broader goals are tied to expectations for greater interaction with others and improvements in the ability to communicate.

I would like for him to become an independent contributing citizen who can take care of himself, cares about others and finds joy in the miracle of life as often as possible.

... I expect my child to thrive. Period. (Parent 165:7)

Major benefits for parents of healthcare service. Parents report receiving several benefits, both formal (including applied behavior analysis (ABA), speech therapy (ST), occupational therapy (OT), physical therapy (PT) and/or medications) and others more informal (general social support and education).

Many parents express burdens with access to healthcare services. A common burden is that there is not enough healthcare available for their child with ASD. Also mentioned were better guidance/education for both parents and doctors on patients' rights; what resources are available and how to access them. Parents claim staff that are available to assist their
Service for children with ASD 
JOSM 31,5

1026

children (e.g. therapists, aides, behaviorists, school psychiatrist/psychologists or counselors) do not have experience with children with ASD. Learning that your child is diagnosed with ASD is also a sensitive issue, and some parents perceived it as a burden needing more support.

Major challenges I have experienced from raising a child with an autism are not able to communicate with the child, not able to accept the diagnosis of my child for a long time, and not able to have exact answers to when she can be 'cured'. (Parent 86:4)

After parents receive the diagnosis for their child, it is a burden if the diagnosis is not taken seriously by educational and healthcare service providers:

The challenges are unending. Lack of support from underfunded school, medical practitioners who believe girls who make eye contact are not autistic, misdiagnosed with anxiety, frequently cancelling events/invitations. (Parent 4:1)

Healthcare service is beneficial for the child, but parents are burdened with the need to integrate different types of care of their child.

Making it easier for parents to find what healthcare service is available to do for children with autism, what the process is to get these resources, how parents can understand what resources are suited to which needs, having competent behaviorists, developmental pediatricians, OT and STs accept healthcare insurance. (Parent 112:5)

In addition to the availability and access to service, in the USA. parents perceive the cost of healthcare service as a burden.

There should be coverage of ABA, speech, PT and OT No matter what plan you have if there is an autism or sensory processing disorder diagnosis. (Parent 113:5)

The most frequently mentioned concern is lack of insurance coverage. Parents see a definite need to expand insurance coverage for diagnosis and speech therapy. Several parents express concerns about healthcare services not being covered or only partly covered by insurance.

He [the child] also attends social skills once a week during Saturday for 2 hours- this is through our healthcare insurance. We usually have to pay for the developmental pediatrician assessment out of pocket as we would have to wait for over 6 months if we go through our insurance provider (Parent 37:2).

The only thing covered by our insurance is ABA therapy. We pay out of pocket for the private speech therapy he receives twice a week outside of school. I do not have out of pocket coverage, so we get No reimbursement. We are spending $\$ 290$ a week on speech. The ABA program - social skills and ABA swim, are covered, so we just pay a $\$ 10$ co-pay. (Parent 38:2).

These parent interviews demonstrate a clear benefit of high quality educational services - e.g. therapists, aides, behaviorists, school psychiatrist/psychologists and counselors - and teachers who have a good understanding of ASD children's needs. Relatedly, parents believe that their children with autism benefit from different types of healthcare service: applied behavior analysis (ABA), speech therapy (ST), occupational therapy (OT), physical therapy (PT), medications. But they also point to significant burdens of both educational and healthcare services for their children with ASD. Lack of integration and availability of services (including lack of competent service providers and challenges with cost) are serious burdens. Furthermore, every child has individual needs, and parents are typically first-timers raising a child with ASD and are therefore challenged in trying to integrate their child's services. Service providers' lack of experience with ASD and people's ignorance of the challenges of ASD, especially with respect to the children's difficulty with understanding social norms exacerbate the problem. 
Findings: service provider interviews

The six educational service providers interviewed included kindergarten teachers, special education teachers, teaching assistants and a speech-language pathologist at an outpatient hospital. The six healthcare service providers interviewed list their roles as doctor/clinician, dentist and mental health provider. Interviews include a relatively small number of healthcare service providers (six respondents), but they span a wide range of fields. All service providers have experience with children with ASD.
Service for children with

ASD

\section{Provider view: major benefits of educational and healthcare service}

Educational service providers perceive the collaborative nature of service among teachers, therapists and healthcare service providers. Parents' involvement in the development of the child's individualized education program (IEP) is also seen as a benefit. Services provided in the educational setting are seen as advantageous because of the extended time and frequency of interaction, which gives educational staff greater familiarity with a child's specific needs.

Another point of emphasis is the importance of early intervention, observation and assessment, which is possible in the educational setting. In addition, providing services in the educational setting does not require parents to make additional trips to outside service providers.

It seems like professionals are willing to collaborate in terms of treatment in order to provide the best possible care. I co-treat with an occupational therapist for many of my children with ASD, which is beneficial for the child as well as for us as educators. I feel like families benefit from this in terms of time (their child receives services from both professions at the same time) and in terms of the feedback, they receive from both of our perspectives. It seems like clinical service is more childfocused than family-focused, which is actually my area of study as a doctoral student (familycentered interventions for children with ASD). (Educational service provider 221:2)

Educational service providers generally agree that expected and ideal outcomes are very individual. As such, most educational service providers describe ideal outcomes in more relativistic terms (e.g. progress, maximum potential, etc.). Several respondents describe an ideal outcome as an ability to cope with everyday life with minimal assistance, optimal happiness and positive interpersonal relationships. In terms of systematic outcomes, one respondent mentioned an ability for educational service providers to provide an education path very early. Better communication among providers is necessary to facilitate this outcome.

It is important to realize that there is No typical outcome one would expect to see with an autistic child. The optimal outcome must be based on the child's levels and what support system they have. Ideally, as an educator, I want to see my children achieve personal growth as a result of their time in my classroom. I want the child to grow from their baseline of skills when they joined me to where they are at the end of the year.

Mostly though, I want my children to have personal successes that lead to happy lives and well developed relationships with others No matter how they communicate. (Educational service provider 236:5)

The primary purpose of medical/dental service is to prevent or treat health-related problems. Common themes can be grouped into two general themes: healthcare treatments and coping mechanisms. However, autistic children can present unique challenges to healthcare treatment, e.g. difficulty expressing themselves, inability/unwillingness to follow instructions, difficulty to stay still (e.g. in dental care, getting a shot, etc.). As a result, parents/caregivers/aids benefit from education on what children are experiencing and how to respond effectively. As such, the potential benefits of clinical services extend beyond the patient to those in the patient's orbit, and as such they often require more and more holistic approach to service. 
JOSM 31,5

1028

\section{Provider view: major burdens of educational and healthcare service}

All of the educational service providers make some reference to potential tension between service providers and parents. They perceive that parents often feel that children are not getting enough service or that services provided by the district are too limited. One respondent points out that parents often have to "stay on top" of providers to ensure that children get the services they are entitled to. Sometimes a child will not bond with a therapist or other service provider, but there are no other options available in the school. Several educational service providers express a concern that what is achieved by service providers during the week is lost on the weekends: that parents have difficulty implementing providers' recommendations at home. Parents frequently want to be more involved, but are unable to, due to logistical concerns (e.g. work) or insufficient knowledge (i.e. cannot remember what to do or did not understand what to do).

Some families may feel that what we do here at school is limited and that they would like to see more services provided to the child (such as extra service times with OT and Speech) or extra services provided to the child over the summer (known as ESY - Extended School Year). Another challenge that I have seen is that sometimes a child does not work well with the OT or Speech Pathologist. But due to budget constraints we only have one service provider for OT and one for Speech provided to our school, so the sessions could be limited when trying to get the child to attend to someone that they do not want to work with. Some families do not show interest in knowing what their child is doing at school and therefore do not apply what was learned at school to home and this limits the child's growth. (Educational service provider 228:3)

Educators agree that improvements are needed in service to help both the parents of and children with ASD. These improvements echo the burdens that the parents perceive: integration and consistency of care in a safe environment with staff that is experienced with children with ASD. For example, one educator references a need for greater consistency in care across settings (e.g. school vs outpatient facility). One respondent expresses a need for a digital way of recording therapies so that parents can better follow their children's progress. A couple of respondents reference challenges in larger environments: in larger districts it is harder to achieve the "whole community brings up the child" approach, whereas in smaller districts it is easier to develop familiarity. Also, reducing class size is helpful. Another respondent makes reference to the servicescape issues - organizing classrooms so that children with ASD do not have to navigate long hallways and reducing overstimulation in service environments more generally.

Finally, respondents indicate that more training should be made available.

I would like to see more thought as to locations of classrooms in the schools. In my opinion if there is a long walk to the class for transitions it makes it hard to assist with parents in view and other students (especially kindergarten children who are experiencing school for the first time). This I feel is also needed in healthcare facilities and other busy common places. Often places like hospitals can be over stimulating, loud, and lengthy waits are hard for anyone. A parent recently commented about how many moves their child had to make during their stay at the hospital. This was very stressful to the person receiving care. (Educational service provider 235:4)

The healthcare service providers echo parents' burdens that resources are inadequate to cover the demand for services. To quote one respondent, "We need to share too few resources for too many." Moreover, to meet the resource needs of families with autistic children, autismspecialized therapists/medical professionals would benefit from more comprehensive and more intensive training. Furthermore, the respondents called for better (insurance/ government) funding for services to compensate healthcare professionals.

Needs more speech therapist or occupational therapist available (readily) at schools. (Healthcare service provider 275:4) 
Furthermore, healthcare service providers confirm parents' burdens with insufficient availability of services because of financial challenges.

ABA services should be available for all children with ASD. Unfortunately, without private insurance, $\mathrm{ABA}$ services are difficult to access in Illinois. Also staff training to ensure [that] services are being implemented correctly. (Healthcare service provider 276:4)

Healthcare service providers see that parents face challenges in finding clinicians with experience in treating patients with autism spectrum disorder. Moreover, diagnoses and treatments are often more difficult. Children with ASD can have anxiety and outbursts. Parents' desire to protect/comfort their child can actually exacerbate the problem.

It is difficult for pediatric patients with ASD to adjust themselves to unfamiliar dental office settings. Like any other patients without ASD, they can experience anxiety and fear - but the expression of such anxiety and fear can lead them to dangerous situations. For example, pediatric patients with ASD tend to express their anxiety physically, i.e. sudden movement: raising hands while dentist/ hygienist working on their mouth, etc. Also, the unique challenge comes from patients' family members as they can be very protective of their children. Their tendency of protection may negatively affect their children and they get more anxious and nervous - that, in fact, is a major obstacle. (Healthcare service provider 270:3)

A significant challenge relates to money in case the service is not offered by public healthcare or covered by insurance. The healthcare service providers broke this into two distinct categories: insurance coverage and poverty. Insurance coverage varies widely. As a result, some services for some patients will not be covered. Poverty exacerbates this problem as parents in these circumstances often lack private insurance to cover services. In addition, poverty adds further hurdles. Specifically, one respondent observes:

It is difficult to find staff that are comfortable traveling to some areas [in which impoverished families live]. Carry over is also difficult due to other variables that low income families face. We have a hard time with families providing materials and keeping the materials intact during home therapy. (Healthcare service provider 269:3)

\section{Provider view: integration of educational and healthcare service}

Both educational and healthcare service providers emphasize the importance of integration of these services. Through support, parents should learn skills themselves that help them to better relate to their child and see growth and improvement in their child.

Ideal outcomes families could expect to see are support from clinical and educational service providers. Families could expect to see growth and change in their child with autism due to the goals that the clinical service and educational service work on each day. (Educational service provider 242:6)

The service providers' view of an ideal outcome of an integrated educational and healthcare service is that autistic children achieve their potential (i.e. "socially significant changes in their skills and maladaptive behaviors"). There was also the stated goal that children with ASD receive the same quality of service for their physical sicknesses as other children.

Expected and ideal outcomes for families focus on the ability to lead a more normal life, some level of independence for the autistic child and the ability to adapt appropriately in social situations. The ultimate goal is happy and fulfilling lives for the autistic child and the family as a whole.

We give families hope that their children can someday be independent adults and live happy and fulfilling lives. (Healthcare service provider 290:6)

Service for children with ASD

\section{.

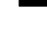


JOSM 31,5

1030

To summarize, both educational and healthcare service providers support parents' needs of integration of services from multiple service providers. Integrated service provided at the school or kindergarten is advantageous because of the extended time and frequency of interaction, which gives staff greater familiarity with the child's specific needs. Furthermore, good collaboration with parents is advantageous. Both educational and healthcare service providers echoed parents' burdens that resources are inadequate to cover the demand for services. More autism-related therapists/medical professionals and special education teachers are needed, as well as better training for these professionals and for parents of children with ASD. Healthcare providers also expressed their worry for families lacking financial resources or insurance coverage for necessary services.

\section{Discussion of findings}

An increasing number of children will be diagnosed with autism spectrum disorder (ASD) globally every year. The available educational and healthcare services, however, are unable to meet the current demand for treatment (Digitale, 2017). Parents are main integrators of long-term service for their children with ASD (Carbone et al., 2010), yet service research has not focused on parents' challenges with services for these parents (and their children). Based on the interview and sentiment analysis, parents perceived two main burdens in obtaining services for their children with ASD: (1) a lack of availability (both access to needed services and financial challenges) and (2) weak integration between healthcare and educational services. By providing researchers, educators, healthcare workers and policymakers with insights into parents' perceptions of the value (i.e. benefits vs burdens) received for their child with ASD from education and healthcare providers, this paper contributes to the ASD literature. These insights may help service providers design innovative service solutions. Such service solutions may provide value to parents and by extension to their children with ASD. Such service solutions may also provide value through service providers who care for children with ASD.

Challenge for parents: lack of available service and cost of service for children with ASD

Several studies in healthcare have found that families with a child with ASD experience difficulty accessing various services when they diligently seek to find the right treatment for their child (Ruble et al., 2005). The findings of this study highlight parents' burdens to find suitable services for their children. Parents' burdens were echoed by the service providers themselves who acknowledged that employees often lack the specialized training and understanding necessary to meet the special needs of children with ASD. Extra services are essential as children with severe symptoms of ASD impact the whole family.

Educational research has emphasized the profound burdens parents and their children with ASD face in their search for service solutions. The reality is that services for children with ASD are long-term investments; there is no "quick fix" treatment, or cure or preventative measure (Humphrey and Lewis, 2008). Furthermore, parents often find themselves unable to adequately deal with their children's commonly exhibited ASD behaviors, which makes social outings with their children difficult (Higgins et al., 2005). Research finds significant levels of depression and stress are often associated with parents of children with ASD (Twoy et al., 2007; Steiner, 2011). To handle stress, families often use different coping strategies. For example, many parents with a child with ASD prefer to withdraw through escape and distancing from stressful situations (Twoy et al., 2007).

The economic burden and inadequate insurance coverage affected many families. In this investigation, parents in the US were concerned with the lack of insurance coverage, especially with getting a diagnosis and speech therapy. The cost of service was part of the availability challenge (particularly if the service was not provided through public healthcare, 
or the service was not covered by insurance). An ASD diagnosis incurs considerable longterm economic costs to the parents in addition to the emotional challenges and special arrangements (Shimabukuro et al., 2017). At the aggregate level in the US, value- based health care (VBHC) has become an important healthcare delivery model (Tsevat and Moriates, 2018). In VBHC, value is defined as health outcomes achieved per dollar spent. According to the VBHC principle, the service is seeking to use limited resources to provide the greatest value instead of volume to patients.

What is a good value in comparison to poor value in healthcare, however, remains ambiguous (Hamid et al., 2014). Investments in services may cost more today but bring longterm savings for the nation as a whole if the child is able to live an independent life as an adult. In practice, diagnosis and healthcare treatment of children with ASD can be challenging. Service researchers can contribute to solving this challenge (for example, by modifying and transferring service design models from long-term services such as insurance and financial service, to models of service for children with ASD).

\section{Challenge for parents: inadequate integration of educational and healthcare service}

The findings show that integration between different types of services improves the service process, outputs and perceived benefits. In the interviews, both educational and healthcare service providers prioritized early treatment of ASD and emphasized that healthcare service providers should be aware of supportive programs and activities to better accommodate parents' and children's needs and conditions. A successful ASD treatment protocol should take into consideration the individual characteristics of the child and family in order to identify meaningful treatment goals and strategies (Hurth et al., 1999). Parents perceived that educational service has a key role for early intervention and continuity of service, and healthcare service should be aligned as part of holistic care for ASD children.

In order to strengthen the integration of family-centered services, effective collaboration and communication between professionals and the parents are necessary, so that parents are empowered with useful information and resources to be able to find the best caregiving activities for their children (Brown et al., 2012; Benevides et al., 2019). Trustworthy relationships between the parents and healthcare providers can significantly influence healthcare outcomes (O'Reilly et al., 2014; Benevides et al., 2019). Children with ASD demonstrated more positive affect, higher levels of responding and appropriate engagement when parents were empowered and involved in the intervention process (Brookman-Frazee and Koegel, 2004).

Recent service research emphasizes that reframing resources is important when the goal is integrated resources and practices (Koskela-Huotari et al., 2016). Danaher and Gallan (2016) point that service integration enables continuity in long-term care. Integrated service for a child with ASD requires integrated resources and practices of educational and healthcare services. The findings show that current integration practices are insufficient. In the interviews, parents' and service providers' wish lists included digital ways of recording therapies and greater consistency in service across school and outpatient facilities. Vink et al. (2019) emphasize that identifying the enabling conditions for service practices is essential for developing service. Parents' burdens give insights into the burdens they have and encourage further research identifying the challenges and possibilities for customeroriented digital tools to facilitate family-school relationships.

This paper has identified parents' perceptions of long-term healthcare and educational service value (i.e. benefits vs burdens) received for their child with ASD. This is the first study to shed light on the perceived value of service for parents with an ASD child from a customercentric service perspective. As access to service is limited and customer-centric service requires integration of healthcare service and educational service, it is important that service providers gain insight into parents' benefits and burdens of service. Integrated service design
Service for children with ASD 
JOSM 31,5

1032

can help families and providers of healthcare and educational services to obtain long-term patient-centric outcomes, which go beyond short-term health outcomes per dollar spent. These insights align with Gallan et al. (2019) who showed that holistically aligning individual customers' and healthcare providers' ecosystems increases community well-being. The authors encourage service researchers to take a more active role in helping to solve the many challenges in integrating healthcare and educational services and especially emphasize a patient-centric approach to value.

\section{Managerial implications}

Service managers are encouraged to alleviate parents' burdens by first gaining an understanding of parents' burdens and then use service design and innovation models to improve services for parents with children with ASD. For managerial purposes, this paper applies the value-centric approach to service design and innovation (Helkkula et al., 2018). Figure 1 shows that parents' burdens make the needs for reshaping the service system explicit. Identifying service benefits reassure service providers about what parents perceive as valuable with the service. Identifying parents' burdens offer service providers useful managerial insights into what elements of the service should be redesigned and innovated. Parents' main burdens of the service for children with ASD are (1) lack of available service and cost of service for children with ASD and (2) inadequate integration of educational and healthcare service. The relevant actors in the service system should shape the system to enable needed service processes.

Processes can generate desired output of the educational and healthcare service to help the child with ASD to manage his or her adult life in a better way.

Lack of available service refers to (1) a lack of service in general and (2) a lack of service providers who are experienced in the ASD-specific services (and have good understanding of and patience with ASD children's needs). Children with ASD may be very selective who (e.g. a therapist) they accept. This creates challenges for service providers when a wide range of options is not available. What service is available for parents and their children with ASD should be collectively reshaped among actors including parents, educational and healthcare service providers and policymakers. Groups of educational and healthcare service providers should enter into dialogue with policymakers to foster an integrated system.

Availability of service includes the cost for the service and whether the service is included within public healthcare. Actors involved should actively transfer their insights to the policy level. The current VBHC approach (Tsevat and Moriates, 2018) does not meet the long-term needs of care for parents of children with ASD. At the individual level, service providers should better inform parents of their options; and financial service providers should inform

Figure 1.

Integrated educational and healthcare service for parents with a child with ASD

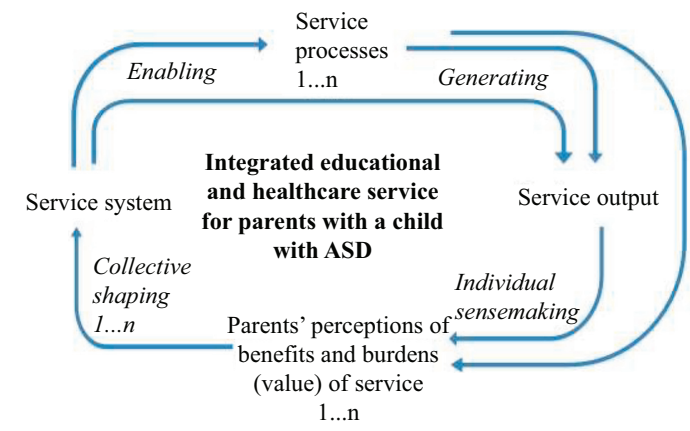


parents of insurance coverage and help parents to manage their budgets given the added costs of service.

An implication for educational and healthcare service providers is to take a patient- centric approach at the systemic level of service. Figure 1 shows that the integrated educational and healthcare service for parents with a child with ASD should (1) set the goal for the common objective/outcome, (2) to decide which specific actors are involved and (3) to determine how resources are distributed among them. Educational services at school or kindergarten should be integrated with healthcare services and play a key role in early intervention and continuity of service. Service given at the kindergarten or school saves parents' additional trips to outside service providers. Processes of care at home should follow the routines that create structure and safety to the child's day so that the achievements during the week at kindergarten or school are not lost on the weekends. Parents should also be given support and guidance as responsibilities with work duties, insufficient knowledge and needs of other family members create challenges in following the child's daily routine at home.

To support the long-term service objectives, interim objectives within a holistic service need to be established for each child. Both educational and healthcare providers require the necessary resources to set these children and their families up for success:

With the support from educational and healthcare [service], the ideal outcome will be children with ASD fully embracing their potentials. (Healthcare provider 288:5)

By "potential," I'm referring to a variety of things: communication, adaptive skills, social skills, occupational skills, ability to develop and maintain healthy relationships, etc. (Educational service provider 239:5)

Recent research (Gallan et al., 2019) emphasizes that healthcare customers need to be treated individually using varied resource combinations to achieve customers' health and well-being goals. Similarly, because ASD is a spectrum, optimal service outcomes will look different for each individual.

\section{Conclusion}

Berry (2019) notes that healthcare service is challenging to improve and requires service design and innovation researchers to participate so that patient-centric perception of value becomes one of its primary aims. In long-term service, such as ASD treatment, the scope of service covers the child's entire life. This investigation examines parents' perceptions of the benefits and burdens associated with healthcare and educational services received by their children with ASD. Parents perceived significant burdens related availability, cost of service and lack of service integration. Parents perceived that educational service has a key role for early intervention and continuity of service, and healthcare service needs to be designed and implemented as part of holistic care for the child. Service providers also recognize the need to better integrate educational and healthcare services. The findings emphasize the need for early intervention, integration and continuity of ASD-specific services, where service providers and families collaborate over time. Service researchers and managers are encouraged to analyze and develop long-term, patient-centric, integrated frameworks and practices in order to alleviate parents' burdens in caring for their children with ASD.

\section{Notes}

1. "Until 2013, there had been four separate diagnoses within the category of autism: autistic disorder, Asperger's syndrome, childhood disintegrative disorder, and pervasive developmental disorder (PDD-NOS)." https://www.everydayhealth.com/autism/types/.

2. https://docs.scrapy.org/en/latest/intro/overview.html (accessed on 1/2/2020).
Service for children with

ASD 
JOSM 31,5

3. https://en.wikipedia.org/wiki/Wrong_Planet (accessed on 1/2/2020).

4. https://wrongplanet.net/about-wrong-planet/ (accessed on 1/2/2020).

5. With regard to "spend", the analysis only looked at the word itself. Clearly, the sentiment score would have been affected by context, but the net effect was that context was more positive than negative when spend was discussed.

\section{References}

Allen, E. and Cowdery, S. (2005), The Exceptional Child: Inclusion in Early Childhood Education, Delmar, Albany, NY.

Amendah, D., Grosse, S.D., Peacock, G. and Mandell, D.S. (2011), "The economic costs of autism: a review", in Amaral, D., Geschwind, D. and Dawson, G. (Eds), Autism Spectrum Disorders, Oxford University Press, Oxford, pp. 1347-1360.

Baio, J., Wiggins, L. and Christensen, D.L. (2018), "Prevalence of autism spectrum disorder among children aged 8 Years - autism and developmental disabilities monitoring network, 11 sites, United States, 2014", MMWR Surveill Summ 2018, Vol. 67 No. SS-6, pp. 1-23, doi: 10.15585/ mmwr.ss6706a1 (accessed 5 January 2020).

Barry, C.L., Kennedy-Hendricks, A., Mandell, D., Epstein, A.J., Candon, M. and Eisenberg, M. (2019), "State mandate laws for autism coverage and high-deductible health plans", Pediatrics, Vol. 143 No. 6, pp. 1-6.

Benevides, T.W., Lee, J., Nwosu, N.A. and Franks, J. (2019), "Understanding the family impact of autism spectrum disorder in a racially and ethnically diverse sample: findings from the national survey of children with special health care needs", Maternal and Child Health Journal, Vol. 23, pp. 951-960.

Berry, L.L. (2019), "Service innovation is urgent in healthcare", Academy of Marketing Science Review, Vol. 9, No. 2, pp. 78-92.

Bitterman, A., Daley, T.C., Misra, S., Carlson, E. and Markowitz, J. (2008), “A national sample of preschoolers with Autism Spectrum Disorders: specialized education services and parent satisfaction", Journal of Autism and Developmental Disorders, Vol. 38 No. 8, pp. 1509-1517.

Bowe, F. (2004), Making Inclusion Work, Prentice Hall, Upper Saddle River, NJ.

Brookman-Frazee, L. and Koegel, R.L. (2004), "Using parent/clinician partnerships in parent education programs for children with autism”, Journal of Positive Behavior Interventions, Vol. 6 No. 4, pp. 95-213.

Brown, H.K., Ouellette-Kuntz, H., Hunter, D., Kelley, E. and Cobigo, V. (2012), "Unmet needs of families of school-aged children with an autism spectrum disorder", Journal of Applied Research in Intellectual Disabilities, Vol. 25 No. 6, pp. 497-508.

Buescher, A.V., Cidav, Z., Knapp, M. and Mandell, D.S. (2014), "Costs of autism spectrum disorders in the United Kingdom and the United States", JAMA Pediatrics, Vol. 168 No. 8, pp. 721-728.

Carbone, P.S., Behl, D.D., Azor, V. and Murphy, N.A. (2010), "The medical home for children with autism spectrum disorders: parent and pediatrician perspectives", Journal of Autism and Developmental Disorders, Vol. 40 No. 3, pp. 317-324.

Chambers, J.G., Shkolnik, J. and Perez, M. (2003), Total Expenditures for Students with Disabilities, 1999-2000: Spending Variation by Disability, American Institutes for Research, Palo Alto, CA, available at: https://files.eric.ed.gov/fulltext/ED481398.pdf (accessed 1 January 2020).

Chang, C.L., Lung, F.W., Yen, C.F. and Yang, P. (2013), "Adaptive behaviors in high- functioning Taiwanese children with autism spectrum disorders: an investigation of the mediating roles of symptom severity and cognitive ability", Journal of Autism and Developmental Disorders, Vol. 43 No. 6, pp. 1347-1355.

Chiri, G. and Warfield, M.E. (2012), "Unmet need and problems accessing core health care services for children with autism spectrum disorder", Maternal and Child Health Journal, Vol. 16 No. 5, pp. 1081-1091. 
Clarke, B.L., Sheridan, S.M. and Woods, K.E. (2009), "Elements of healthy family-school relationships", in Christenson, S.L. and Reschly, A.L. (Eds), Handbook of School-Family Partnerships, Routledge, New York, NY, pp. 61-79.

Cosden, M., Koegel, L.K., Koegel, R.L., Greenwell, A. and Klein, E. (2006), "Strength based assessment for children with autism spectrum disorders", Research and Practice for Persons with Severe Disabilities, Vol. 31 No. 2, pp. 134-143.

Danaher, T.S. and Gallan, A.S. (2016), "Service research in health care: positively impacting lives", Journal of Service Research, Vol. 19 No. 4, pp. 433-437.

De Boer, S. and Simpson, R. (2009), Successful Inclusion for Students with Autism: Creating a Complete, Effective ASD Inclusion Program, Jossey-Bass, San Francisco, CA.

De Mattei, R., Cuvo, A. and Maurizio, S. (2007), "Oral assessment of children with an autism spectrum disorder", Journal of Dental Hygiene, Vol. 81 No. 3, pp. 1-11.

De Winter, M., Baerveldt, C. and Kooistra, J. (1999), "Enabling children: participation as a new perspective on child-health promotion”, Child: Care, Health, and Development, Vol. 25 No. 1, pp. 15-23.

Deardorff, J. (2008), “A road to recovery", Chicago Tribune, 11 May, available at: https:/www. chicagotribune.com/news/ct-xpm-2008-05-11-0805100369-story.html (accessed 4 January 2020).

Digitale, E. (2017), Scientists Crowdsource Autism Data to Learn where Resource Gaps Exist, Stanford Medicine News Center, 8 May, available at: http://med.stanford.edu/news/all-news/2017/05/ scientists-crowdsource-autism-data-to-find-resource-gaps.html (accessed 5 January 2020).

Duker, L.I.S., Henwood, B.F., Bluthenthal, R.N., Juhlin, E., Polido, J.C. and Cermak, S.A. (2017), "Parents' perceptions of dental care challenges in male children with autism spectrum disorder: an initial qualitative exploration”, Research in Autism Spectrum Disorders, Vol. 39, pp. 63-72.

Dunlap, G. and Fox, L. (1999), "Supporting families of young children with autism”, Infants and Young Children, Vol. 12 No. 2, pp. 48-54.

Dyke, P., Buttigieg, P., Blackmore, A.M. and Ghose, A. (2006), "Use of the measure of process of care for families (MPOC-56) and service providers (MPOC-SP) to evaluate family-centred services in a paediatric disability setting", Child: Care, Health and Development, Vol. 32 No. 2, pp. 167-176.

Gallan, A.S., Janet, R., McColl-Kennedy, J.R., Tatiana Barakshina, T., Figueiredo, B., Go Jefferies, J., Gollnhofer, J., Hibbert, S., Luca, N., Roy, S., Spanjol, J. and Winklhofer, H. (2019), “Transforming community well-being through patients' lived experiences", Journal of Business Research, Vol. 100, pp. 376-391.

Garbacz, S.A., Sheridan, S.M., Koizol, N.A., Kwon, K. and Holmes, S.R. (2015), "Congruence in parentteacher communication: implications for the efficacy of CBC for students with behavioral concerns", School Psychology Review, Vol. 44 No. 2, pp. 150-168.

Garbacz, S.A., McIntyre, L.L. and Santiago, R.T. (2016), "Family involvement and parent- teacher relationships for students with Autism Spectrum Disorders", School Psychology Quarterly, Vol. 31 No. 4, pp. 478-490.

Hamid, K.S., Nwachukwu, B.U. and Ellis, S.J. (2014), "Competing in value-based health care: keys to winning the foot race", Foot and Ankle International, Vol. 35 No. 5, pp. 519-528.

Helkkula, A., Kowalkowski, C. and Tronvoll, B. (2018), "Archetypes of service innovation: implications for value cocreation”, Journal of Service Research, Vol. 21 No. 3, pp. 284-301.

Higgins, D.J., Bailey, S.R. and Pearce, J.C. (2005), "Factors associated with functioning style and coping strategies of families with an autism spectrum disorder", Autism, Vol. 9 No. 2, pp. 125-137.

Hinton, S., Sofronoff, K. and Sheffield, J. (2008), "Training teachers to manage students with Asperger's syndrome in an inclusive classroom setting", Australian Educational and Developmental Psychologist, Vol. 25 No. 2, pp. 34-48.
Service for children with ASD

1035 
JOSM 31,5

Hodgetts, S., Nicholas, D., Zwaigenbaum, L. and McConnell, D. (2013), "Parents' and professionals' perceptions of family-centered care for children with autism spectrum disorder across service sectors”, Social Science and Medicine, Vol. 96, pp. 138-146.

Horrocks, J., White, G. and Roberts, L. (2008), "Principals' attitudes regarding inclusion of children with autism in Pennsylvania public schools", Journal of Autism and Developmental Disorders, Vol. 38 No. 8, pp. 1462-1473.

Hsu, J. (2018), "Why are there so few autism specialists?", Scientific American, Vol. 27 November, available at: https://www.scientificamerican.com/article/why-are-there-so-few-autism-speci-alists/ (accessed 5 January 2020).

Huebner, C.E., Chi, D.L., Masterson, E. and Milgrom, P. (2015), "Preventive dental health care experiences of preschool-age children with special health care needs", Special Care in Dentistry, Vol. 35 No. 2, pp. 68-77.

Humphrey, N. and Lewis, S. (2008), “Make me normal': the views of and experiences of pupils on the autistic spectrum in mainstream secondary school”, Autism, Vol. 12 No. 1, pp. 23-46.

Hurth, J., Shaw, E., Izeman, S., Whaley, K. and Rogers, S. (1999), "Areas of agreement about effective practices among programs serving young children with autism spectrum disorders", Infants and Young Children, Vol. 12 No. 2, pp. 17-26.

Hutto, C.J. and Gilbert, E. (2014), "VADER: a parsimonious rule-based model for sentiment analysis of social media text", Proceedings of the Eighth International AAAI Conference on Weblogs and Social Media in Ann Arbor, Michigan, USA, from 1-4 June, pp. 216-225.

Jaber, M.A. (2011), "Dental caries experience, oral health status and treatment needs of dental patients with autism", Journal of Applied Oral Science, Vol. 19 No. 3, pp. 212-217.

Koskela-Huotari, K., Edvardsson, B., Jonas, J.M., Sörhammar, D. and Witell, L. (2016), "Innovation in service ecosystems: breaking, making and maintaining institutionalized rules of resource integration", Journal of Business Research, Vol. 69 No. 8, pp. 2964-2971.

Landers, R.N. and Behrend, T.S. (2015), "An inconvenient truth: arbitrary distinctions between organizational, mechanical turk, and other convenience samples", Industrial and Organizational Psychology, Vol. 8 No. 2, pp. 142-164.

Lavelle, T.A., Weinstein, M.C., Newhouse, J.P., Munir, K., Kuhlthau, K.A. and Prosser, L.A. (2014), "Economic burden of childhood autism spectrum disorders", Pediatrics, Vol. 133 No. 3, pp. 520-529.

Lewis, C., Robertson, A.S. and Phelps, S. (2005), "Unmet dental care needs among children with special health care needs: implications for the medical home”, Pediatrics, Vol. 116 No. 3, pp. 426-431.

Lindsay, S., Proulx, M., Thomson, N. and Scott, H. (2013), "Educators' challenges of including children with autism spectrum disorder in mainstream classrooms", International Journal of Disability, Development and Education, Vol. 60 No. 4, pp. 347-362.

Liptak, G.S., Stuart, T. and Auinger, P. (2006), "Health care utilization and expenditures for children with autism: data from US national samples", Journal of Autism and Developmental Disorders, Vol. 36 No. 7, pp. 871-879.

MacDonald, R., Parry-Cruwys, D. and Dupere, S. and Ahearn, W. (2014), "Assessing progress and outcome of early intensive behavioral intervention for toddlers with autism", Research in Developmental Disabilities, Vol. 35 No. 12, pp. 3632-3644.

MacFarlane, J.R. and Kanaya, T. (2009), "What does it mean to be autistic? Inter-state variation in special education criteria for autism services", Journal of Child and Family Studies, Vol. 18, No. 6, pp. 662-669.

Magi, M. and Allander, E. (1981), "Towards a theory of perceived and medically defined need", Sociology of Health and Illness, Vol. 3 No. 1, pp. 49-71.

Mandell, D.S., Novak, M. and Zubritsky, C.D. (2005), "Factors associated with age of diagnosis among children with autism spectrum disorders", Pediatrics, Vol. 116 No. 6, pp. 1480- 1486. 
Matson, M.L., Mahan, S. and Matson, J.L. (2009), "Parent training: a review of methods for children with autism spectrum disorders", Research in Autism Spectrum Disorders, Vol. 3 No. 4, pp. 868-875.

McGregor, E. and Campbell, E. (2001), "The attitudes of teachers in Scotland to the integration of children with autism into mainstream schools", Autism, Vol. 5 No. 2, pp. 189-207.

Minke, K.M., Sheridan, S.M., Kim, E.M., Ryoo, J.H. and Koziol, N.A. (2014), "Congruence in parentteacher relationships: the role of shared perceptions”, Elementary School Journal, Vol. 114 No. 4, pp. 527-546.

Owens, P.L., Kerker, B.D., Zigler, E. and Horwitz, S.M. (2006), "Vision and oral health needs of individuals with intellectual disability", Mental Retardation and Developmental Disabilities Research Reviews, Vol. 12 No. 1, pp. 28-40.

O'Reilly, M., Karim, K. and Lester, J.N. (2014), "Separating 'emotion' from 'the science': exploring the perceived value of information for parents and families of children with autistic spectrum disorder", Clinical Child Psychology and Psychiatry, Vol. 20 No. 3, pp. 500-514.

Pandey, P. (2018), "Simplifying sentiment analysis using VADER in Python (on social media text)", available at: https://medium.com/analytics-vidhya/simplifying-social-media-sentiment-analysisusing-vader-in-python-f9e6ec6fc52f (accessed 3 January 2020).

Patricio, L., Gustafsson, A. and Fisk, R. (2018), "Upframing service design and innovation for research impact”, Journal of Service Research, Vol. 21 No. 1, pp. 3-16.

Plienis, A.J., Robbins, F.R. and Dunlap, G. (1988), "Parent adjustment and family stress as factors in behavioral parent training for young autistic children", Journal of Multihandicapped Person, Vol. 1 No. 1, pp. 31-52.

Robertson, S.M. and Ne'eman, A.D. (2008), “Autistic acceptance, the college campus, and technology: growth of neurodiversity in society and academia", Disability Studies Quarterly, Vol. 28 No. 4, available at: https://dsq-sds.org/article/view/146/146 (accessed 1 January 2020).

Ruble, L., Heflinger, C., Renfrew, J. and Saunders, R. (2005), "Access and service use by children with autism spectrum disorders in medicaid managed care", Journal of Autism and Developmental Disorders, Vol. 35 No. 1, pp. 3-13.

Sansosti, F.J., Lavik, K.B. and Sansosti, J.M. (2012), "Family experiences through the autism diagnostic process", Focus on Autism and Other Developmental Disabilities, Vol. 27 No. 2, pp. 81-92.

Shevell, M.I., Majnemer, A., Rosenbaum, P. and Abrahamowicz, M. (2001), "Profile of referrals for early childhood developmental delay to ambulatory subspecialty clinics", Journal of Child Neurology, Vol. 16 No. 9, pp. 645-650.

Shimabukuro, S., Daley, D., Thompson, M., Laver-Bradbury, C., Nakanishi, E. and Tripp, G. (2017), "Supporting Japanese mothers of children with ADHD: cultural adaptation of the new forest parent training programme", Japanese Psychological Research, Vol. 59 No. 1, pp. 35-48.

Shimabukuro, T.T., Grosse, S.D. and Rice, C. (2008), "Medical expenditures for children with an autism spectrum disorder in a privately insured population", Journal of Autism and Developmental Disorders, Vol. 38 No. 3, pp. 546-552.

Sices, L., Feudtner, C., McLaughlin, J., Drotar, D. and Williams, M. (2003), "How do primary care physicians identify young children with developmental delays? A national survey", Journal of Developmental and Behavioral Pediatrics, Vol. 24 No. 6, pp. 409-417.

Smith, E. and Brown, C. (2000), "Creating an autism friendly environment", Educational Psychology in Scotland, Vol. 5 No. 3, pp. 23-25.

Stein, L.I., Polido, J.C., Najera, S.O.L. and Cermak, S.A. (2012), "Oral care experiences and challenges in children with autism spectrum disorders", Pediatric Dentistry, Vol. 34 No. 5, pp. 387-391.

Steiner, A.M. (2011), “A strength-based approach to parent education for children with autism”, Journal of Positive Behavior Interventions, Vol. 13 No. 3, pp. 78-190.
Service for children with ASD 
JOSM 31,5

Symes, W. and Humphrey, N. (2010), "Peer-group indicators of social inclusion among pupils with autistic spectrum disorders in mainstream secondary schools", School Psychologist, Vol. 31 No. 5, pp. 478-494.

Szalavitz, M. (2007), “Gifted? Autistic? Or just quirky?” The Washington Post, 27 February, p. HE01, available at: https://www.creativitypost.com/article/gifted_autistic_or_just_quirky (accessed 1 January 2020).

Thomas, K.C., Williams, C.S., deJong, N. and Morrissey, J.P. (2016), "Examination of parent insurance ratings, child expenditures, and financial burden among children with autism: a mismatch suggests new hypotheses to test", Pediatrics, Vol. 137 No. S2, pp. S186-S195.

Toussaint, J.S. and Berry, L.L. (2013), "The promise of lean in healthcare", Mayo Clinic Proceedings, Vol. 88 No. 1, pp. $74-82$.

Tsevat, J. and Moriates, C. (2018), "Value-based health care meets cost-effectiveness analysis", Annals of Internal Medicine, Vol. 169 No. 5, pp. 329-332.

Twoy, R., Connolly, P.M. and Novak, J.M. (2007), “Coping strategies used by parents of children with autism", Journal of the American Academy of Nurse Practitioners, Vol. 19 No. 5, pp. 251-260.

U.S. Census Bureau (2007), "United States S1401 school enrollment”, available at: https://factfinder.census. gov/faces/tableservices/jsf/pages/productview.xhtml?src=bkmk (accessed 4 January 2020).

Vink, J., Edvardsson, B., Wetter-Edman, K. and Tronvoll, B. (2019), "Reshaping mental modelsenabling innovation through service design", Journal of Service Management, Vol. 20 No. 1, pp. 75-104.

Wagner, A.E. and Lockivood, S.L. (1994), "Pervasive developmental disorders: dilemmas in diagnosing very young children”, Infants and Young Children, Vol. 6 No. 4, pp. 21-32.

Warnock, M. (2005), Special Educational Needs: A New Look, Philosophy of Education Society of Great Britain, London.

Wilmhurst, L. and Brue, A. (2010), The Complete Guide to Special Education, Jossey-Bass, San Francisco, CA.

Woodside, J.M., Rosenbaum, P.L., King, S.M. and King, G.A. (2001), "Family-centered service: developing and validating a self-assessment tool for pediatric service providers", Children's Health Care, Vol. 30 No. 3, pp. 237-252.

\begin{abstract}
About the authors
Anu Helkkula is the $\mathrm{PhD}$ programme manager at Hanken School of Economics, and Adjunct Professor, University of Naples "Federico II", Italy. Her areas of expertise include service experience, value cocreation and service design and innovation. Her research has appeared in wide range of journals and edited books, and she is the member of Editorial Boards of highly rated academic journals. She has worked in various industrial research projects. She is interested in the context of healthcare service, intelligent technology, service culture, sustainability-oriented service development, ethical values and value experiences. Anu Helkkula is the corresponding author and can be contacted at: anu.helkkula@hanken.fi

Alexander John Buoye is an associate professor of marketing at St. John's University Peter J. Tobin College of Business. His research focuses on customer experience and its relationship to loyalty and firm performance. Prior to his career in academia, professor Buoye was head of loyalty analytics and senior Vice President at Ipsos Loyalty. His research has been published in such journals as Harvard Business Review, MIT Sloan Management Review, Journal of Service Research, Journal of Business Research, Journal of Service Management, Journal of Interactive Marketing and Journal of Services Marketing.

Hyeyoon Choi is assistant professor and the program coordinator in the Restaurant, Hotel and Tourism program. Her research has a customer-behavior orientation in the hospitality industry and fits within the larger context of service management and operations. It includes hotel operations, environmentally friendly behaviors and health and wellness service. She has published in numerous journals, including Journal of Service Management, International Journal of Hospitality Management, and Journal of Travel Research. She has presented at numerous national and international conferences and received two best paper awards - TOSOK International Tourism Conference held at PyeongChang,
\end{abstract}


Korea and Asia Pacific Council on Hotel, Restaurant and Institutional Education (ApacCHRIE) Conference held in Guangzhou, China.

Min Kyung Lee earned a Ph.D. degree in operations management and is an assistant professor at the Department of Management at the Hankamer School of Business at Baylor University. Dr. Lee spent two years in an automotive industry as a logistic coordinator prior to working on her $\mathrm{PhD}$. Her research broadly explores the notion of customer value creation through the introduction and deployment of new service innovations. Her primary research area pertains to the service science aspects of service operations strategy and design for customer experience.

Stephanie Q. Liu is an assistant professor of consumer sciences at The Ohio State University. Her research focuses on consumer behavior and marketing strategies related to experiential consumption, with special interests in three strategic themes: service encounter management, advertising and social media and technology innovations in the service industry. Her research has been published in leading service management journals and has received media coverage by $50+$ national and international news outlets including the Forbes, Fox and NPR.

Timothy Lee Keiningham is the J. Donald Kennedy Endowed Chair in e-commerce and professor of marketing at St. John's University Peter J. Tobin College of Business. Dr. Keiningham received the American Marketing Association's Christopher Lovelock Career Contributions to the Services Discipline Award for teaching, research and service that has had the greatest long-term impact on the development of the services discipline. His research has received several awards, including best paper awards in the Journal of Marketing (twice), Journal of Service Research, Journal of Service Management (twice), and Journal of Service Theory and Practice (twice).

\section{Service for children with ASD}

1039

For instructions on how to order reprints of this article, please visit our website: 